\title{
Linguagem e inconsciente em Lacan
}

\author{
Ana Carolina Soliva Soria
}

Professora do Departamento de Filosofia e Metodologia das Ciências da UFSCar 

No início de seu artigo "Sobre a etiologia da histeria", publicado em 1896 no livro Estudos sobre histeria, Freud descreve o que entendia ser o cerne de sua conquista científica, a saber: encontrar a vivência que possibilitou a contração dos sintomas histéricos através da "investigação anamnésica" dos enfermos. Ao contrário da opinião na época difundida em meio aos médicos, a carga hereditária e as diferenças anatômicas não teriam um papel fundamental na determinação da enfermidade para Freud; esse papel seria atribuído às consequências psíquicas da vivência traumática. Para fundamentar a cura sobre a investigação das recordações das vivências traumáticas, Freud teve de recusar a ideia de que a enfermidade psíquica tivesse sua origem diretamente relacionada com o funcionamento fisiológico, aos moldes de um autômato mecânico que impossibilitasse o enfermo de qualquer discernimento acerca de seu próprio estado. O que Freud fez foi subverter o método terapêutico difundido em sua época, que dava ao médico todo o saber acerca das degenerações fisiológicas que provocariam os estados psíquicos alterados. Diante de tais degenerações defendidas pelos médicos, nada mais restaria ao paciente do que se calar; isso porque, ao atribuir a origem da enfermidade à alteração fisiológica, o sintoma estaria destituído de sentido. A grande contribuição científica de Freud, o que lhe permitiu escapar de reduzir a enfermidade psíquica ao campo do hereditário e do fisiológico defendida ferozmente pelos médicos de sua época, segundo afirma o próprio psicanalista, foi dar voz ao enfermo e, pela investigação da memória, atribuir realidade e sentido ao seu sintoma.

Antes mesmo de publicar A interpretação dos sonhos, de 1900, obra que para muitos inauguraria a psicanálise, Freud havia deslocado para segundo plano o funcionamento somático-hereditário, para o qual era dada a primazia pelos médicos de sua época, e colocado em seu lugar a vivência patológica da infância que, como "símbolo mnêmico" (Erinnerungssymbole) (Freud 1999, p. 427), ganharia novamente expressão na vida adulta. A investigação 
do relato do enfermo que deu voz aos seus pacientes revelaria a ofensa sofrida no passado. Um novo método estava por nascer, a saber: a associação livre.

A atitude autêntica de Freud, que o acompanhou ao longo de seus 40 anos de exercício da psicanálise, não foi ignorada por Jacques Lacan. Assim como Freud, o psicanalista francês afirma que as pulsões, as resistências, a associação livre não se dariam em termos neurológicos ou não se reduziriam ao fisiológico - o que colocaria a psicologia sob a tutela de outras disciplinas. Para Lacan, se esses eventos, ligados à realização do desejo, se dão a conhecer desde a origem até os seus efeitos pela palavra, eles denotam processos inerentes à própria linguagem.

Segundo Joël Dor (2003, p. 28 e segs. ), a tarefa de resgatar a importância da palavra e atribuir clara prioridade ao simbolismo, tarefa que Lacan acreditava estar diminuída dentre os psicanalistas que sucederam Freud, seria conduzida por uma distinção fundamental tomada da linguística de Saussure, qual seja: a diferenciação entre significante e significado. Deslizando de significante em significante, Lacan encontrará o sujeito, não o sujeito da consciência ou um sujeito sobre o qual recairia o peso da existência, mas o sujeito do desejo incessantemente à procura da última palavra que lhe permita alcançar a causa de seu desejo e pôr fim a ele.

Como veremos ao longo desta exposição, Lacan nunca deixou de se considerar um freudiano. Mais do que isso: ao levar em consideração as palavras de Dor acima mencionadas, Lacan pensava que os psicanalistas que sucederam Freud não compreenderam e mesmo minimizaram a importância do elemento fundamental para o pensamento do autor de A interpretação dos sonhos, a saber: o papel que a palavra assume para a intelecção do inconsciente e, por consequência, a relevância da linguagem para a análise da vida psíquica. Lacan irá, portanto, destacar uma relação que, aos seus olhos, seria indissociável, mais especificamente, a relação entre inconsciente e linguagem e, a partir dela, 
retomar em uma nova chave (uma chave que lhe é própria) um tema já presente em Freud (qual seja: o do simbolismo), pelo qual o psicanalista austríaco podia atribuir sentido às fantasias de seus pacientes, traduzindo (übersetzen, para usarmos um termo do próprio Freud) para uma linguagem inteligível as produções enigmáticas dos delírios, sonhos e fantasias de casos como Dora, Hans, Schreber e muitos outros.

Embora a possibilidade de uma tradução, e mesmo, de um significado (Bedeutung) ou interpretação (Deutung) do que se passa nos sonhos ou nos delírios possa sugerir que no inconsciente exista uma linguagem, Freud não afirma explicitamente que eles sejam uma estrutura comunicativa ou que os problemas da linguagem se colocam para o inconsciente. Em A teoria freudiana do sonho, Monzani (2005, p. 139) escreve que o mundo do sonho e das formações patológicas é "um mundo privado, não comunicado"; para Wollheim, em seu artigo "O gabinete do Dr. Lacan", se tomarmos a própria letra de Freud, a questão da linguagem ficaria sempre em segundo plano. Mas é justamente aí que Lacan verá um problema que não estará presente apenas em sua obra, mas na constituição da psicologia como uma disciplina autônoma. Em "Lacan: biologia e narcisismo", Bento Prado Jr. afirma que a relação indissociável que se cria entre linguagem e inconsciente impede a redução do campo psicológico ao mecânico das funções fisiológicas. Com Lacan, a psicologia incorpora um tema contemporâneo, de matriz saussuriana, e muito presente nas filosofias do século XX, a saber: a linguagem. Entender como Lacan traz ao domínio da investigação psicológica esse tema é um modo de compreender um dos problemas que constituem a própria psicologia como âmbito de pensamento autônomo. Freudiano à sua maneira, Lacan nos dá a oportunidade de entender, mediante a linguagem, um problema paradigmático para a intelecção do movimento que constitui a investigação psicológica. Nosso intuito nessa exposição é o de analisar o modo como Lacan opera essa releitura do texto freudiano, trazendo a linguagem para o centro 
de seu pensamento e vendo nela o campo em que se estrutura o inconsciente.

A fim de expor as imbricações entre linguagem e inconsciente, o presente estudo se detém em três pontos do pensamento lacaniano, a saber: 1. Como a linguagem da literatura ou do homem de letras converge com a linguagem do inconsciente; 2 . As consequências da apropriação da linguística pela psicanálise - o que permitiria a Lacan propor a supremacia do significante sobre o significado e a dominação do sujeito pelo significante; 3. E, por fim, a distinção entre os conceitos de desejo e demanda - distinção que permite a Lacan priorizar o simbolismo na determinação do sujeito e do desejo e escapar do reducionismo biológico.

\section{O homem das letras, suas obras e a psicanálise}

Em uma homenagem à Marguerite Duras, Lacan (1956, p. 7-15) escreve que mesmo se a escritora lhe dissesse não saber de onde provém o material para suas criações, teria de reconhecer, assim como Freud, "que no que lhe concerne, o artista sempre o precede e que ele só faz psicologia aí onde o artista lhe aplaina a via" (Id., Ibid.).

Assim como Freud a respeito da Sófocles, Shakespeare ou Jensen, Lacan, ao falar de Marguerite Duras, reconhece que o trabalho do artista, do homem de letras, precede o trabalho do investigador psicológico e aponta o caminho para ele. Duras sabe o que o psicanalista também sabe - seu saber é o mesmo que Lacan professa em seus seminários sem que ela jamais tenha escutado nenhuma preleção do psicanalista francês. A justificativa que Lacan apresenta para isso é "que a prática da letra (lettre) converge com o uso do inconsciente" (Id., Ibid.). Há para Lacan algo na prática do artista que é o mesmo que opera na prática analítica. Lacan não quer dizer que o poeta ou o romancista exponha algo da psicanálise mediante conceitos acabados e bem formulados, nem que a arte é um esboço rudimentar esperando que o psica- 
nalista venha lhe dar o acabamento final. O psicanalista francês não tem a intenção de colocar as artes num plano inferior ao da psicanálise ou subordinar as artes à ciência. Ao contrário, afirma apenas que aquilo que faz o escritor (ou seja, a prática da escritura) toca, se assim podemos dizer, o real da prática analítica. Em outros termos, Sófocles, Shakespeare, Jensen ou Duras expõem ao psicanalista algo da ordem do desejo, mais precisamente: a relação do desejo com a linguagem.

É nesse sentido que Lacan dá ouvidos a um conto de Edgar Allan Poe, intitulado A carta roubada. Esse texto é tomado pelo psicanalista para exemplificar um saber que Allan Poe compartilha com a psicanálise, isto é: o princípio da supremacia do significante sobre o significado.

Nesse conto, Allan Poe apresenta diversos personagens que se mobilizam em torno da posse de uma carta. E o movimento do conto segue a circulação da carta. Para darmos uma ideia geral do texto de Allan Poe, sintetizaremos as duas cenas em que Lacan concentra a sua análise. A trama se passa em Paris. Na primeira cena analisada por Lacan, uma pessoa da mais nobre estirpe encontra-se sozinha e recebe uma carta. Essa ilustre pessoa é a rainha. Na sequência, entram em cena o rei e o ministro e se torna evidente o embaraço da rainha em relação à carta - esta, segundo fica claro, poderia pôr em dúvida a honra e a segurança da nobre dama. A rainha tenta dissimular a carta colocando-a sobre a mesa, virada para baixo. O rei não percebe nada; ao ministro, contudo, com seus olhos de lince, diz Lacan, nada escapa. Ele tira do bolso um papel semelhante ao da carta, finge lê-lo ostensivamente, e o substitui pela carta sem que a rainha possa fazer nada. Para não chamar a atenção do rei, a rainha não demonstra sua perplexidade. A cena termina com a rainha sabendo que o ministro se apropriou da carta e este ciente de que ela percebeu sua artimanha.

Na segunda cena, temos um novo personagem: Dupin. Por ordem do comissário de polícia, Dupin visita o gabinete do ministro, em sua mansão. O ministro, desconfiado do motivo da visita, 
recebe Dupin como se não houvesse nada a esconder em seu gabinete. A displicência do ministro não engana, porém, o visitante. Dupin percebe um bilhete amassado, colocado à vista de todos num porta-cartas qualquer. Ele sabe que é o que procura e retira-se do gabinete após ter "esquecido" sua tabaqueira sobre a mesa. No dia seguinte o visitante retorna ao gabinete sob o pretexto de recuperar o objeto lá deixado, agora munido de um papel semelhante ao da carta roubada, um fac-símile, nas palavras de Lacan. Um evento na rua, previamente preparado para este intento, atrai o ministro para perto da janela, e muito rapidamente Dupin substitui a carta pelo papel que trouxe consigo. Com a intenção de dar uma pista para o ministro de quem o ultrapassou em astúcia, no fac-símile deixado por Dupin no gabinete encontra-se a seguinte frase:

“... Um desígnio tão funesto, se não é digno de Atreu, é digno de Tieste.” (Lacan 1966, p. 14).

O resultado final da segunda cena é: o ministro nada sabe sobre a substituição da carta, a rainha sabe de tudo.

\section{A apropriação da linguística pela psicanálise}

Segundo Wollheim (1990, p. 214), há na totalidade dos escritos do psicanalista francês uma escassez de exemplos que lhe daria um caráter mais abstrato e também mais árido do que, por exemplo, os textos de Freud. Ora, se nos fiarmos nessa afirmação, podemos tomar o seminário A carta roubada como um momento privilegiado para se esclarecer, mediante ilustração, um problema de importância capital para Lacan, a saber: a de que há uma "determinação fundamental que o sujeito recebe do percurso de um significante"(Lacan 1966, p. 12).

Em sua análise do conto, Lacan estabelece uma analogia entre o percurso da carta roubada da rainha e o percurso do signifi- 
cante (donde o jogo em francês com a palavra Lettre, que significa carta e letra ao mesmo tempo). E para melhor compreendermos o modo como Lacan irá se apropriar do saber de Allan Poe para expor a analogia da carta com o significante tomemos algumas considerações feitas pelo psicanalista francês acerca da linguística de Saussure em seu escrito A instância da letra (lettre) no inconsciente ou a razão desde Freud ${ }^{1}$. Neste texto, Lacan apresenta o signo como um complexo constituído por dois elementos distintos: o significante e o significado. Entre ambos os elementos não haveria uma relação fixa e necessária, ou ainda, natural - essa relação é fabricada pela comunidade linguística. Tal como expõe Lacan, a confecção do signo revela o seu caráter arbitrário. Uma vez ligados significante e significado, o signo se impõe à comunidade linguística como imutável - a comunidade perderia a sua dimensão arbitrária, passando a compreendê-lo como uma ligação fixa e necessária entre um significante e um significado. Tomados isoladamente, os signos são elementos pontuais e nos dão apenas um léxico. Para além do léxico, existem leis que articulam os signos entre si e dão à língua um caráter vivo e móvel². São essas leis que interessam Lacan. Segundo o psicanalista, as regras de articulação entre os signos não recaem diretamente sobre o significado, isto é, a significação não estaria determinada pelo conteúdo/conceito da coisa. Tomemos o exemplo do conto para ilustrar essa ideia: tal como exposto por Allan Poe, os personagens viram-se mobilizados pela posse da carta, e não pelo conteúdo dela, pois este não é revelado em nenhum momento. A significação é, assim, secundária: ela é obtida, segundo Lacan, da delimitação de um significante frente ao conjunto de significantes (Lacan 1966, p. 515). Qualquer conversa entre duas pessoas pode nos exemplificar o que Lacan

1 Os pronunciamentos Le séminaire sur "La Lettre volée" e L'instance de la lettre dans l'inconscient ou la raison depuis Freud são, respectivamente, de 1955 e 1957.

2 Vale aqui lembrar que Lacan, em seu seminário sobre A carta roubada nos diz que a letra mata (p. 24). Exemplo disso é a castração. Por outro lado, a letra tem um caráter construtivo: ela é constitutiva do sujeito e do desejo. 
quer nos fazer compreender: o significado de uma sentença, de uma frase dita em uma conversa, somente pode aparecer após a frase ter sido dita. As palavras são expressas linearmente no tempo (para frente, digamos) e o significado é alcançado retroativamente. O significante precederia, assim, o significado.

O que queremos dizer é que, para o psicanalista francês, a busca da significação é oferecida apenas nas correlações significantes: o significado jamais tem a primazia sobre o significante e está em uma posição secundária frente a este. Não é à toa que Lacan inverte o algoritmo de Saussure: de "significado sobre significante" (s/S) para "significante sobre significado" (S/s), com a intenção de mostrar que o significado está sob, que coloca-se abaixo, sob a guarda do significante. Lacan escreve: "Impõe-se, pois, a noção de um deslizamento incessante do significado sob o significante" (Lacan 1966, p. 502).

Mas, por que o psicanalista deveria recorrer à linguística para expor algo da ordem do patológico? Tal como dissemos acima, a tradição fixa certos signos que muitas vezes podem nos fazer pensar numa ligação necessária entre um significante e um significado. Perde assim a arbitrariedade do signo. Contudo, dirá Lacan, os sonhos, os atos falhos, o discurso poético, o discurso dos enfermos nos revelam algo que o discurso comum esconde: ao contrário da ligação fixa entre significante e significado dada pela tradição, um significante pode se ligar a uma infinidade de significados. Essa flexibilidade da língua não pode ser revelada pelo exame do signo (que é pontual), mas pelas leis de articulação significante. O caráter primordial do significante (seu poder de delimitar o significado) ganha em Lacan um testemunho incontestável com a análise dos processos metafóricos e metonímicos do discurso, isto é, dos processos de superposição e substituição significantes (aos quais Lacan identificou ao que Freud denominou condensação e deslocamento). Lacan não busca na língua já cristalizada pela tradição o percurso do significante (pois nela o que é inicialmente movimento já foi fixado). Ele buscará o caráter móvel da língua 
nos momentos de quebra com a língua cristalizada. O discurso dos sonhos, dos enfermos, os atos falhos etc. nos mostram uma brecha, uma lacuna no próprio dizer do sujeito: algo é dito sem que o sujeito possa ter o controle disso ou saber o seu significado. Essas brechas da linguagem revelam, segundo Lacan, algo constitutivo do sujeito: há uma falta que dá forma ao próprio sujeito³.

Retornemos ao seminário da Carta roubada e ao problema da primazia do significante sobre o significado. Antes de mais nada, é preciso lembrar que o psicanalista atribui à carta a função de significante e ao seu conteúdo a função de significado. O que o conto ilustra é esse caráter móvel do significante, que escapa de nossas mãos sem que possamos fazer nada. No sonho, ato falho, chiste, sintoma, construção poética etc. o significante se impõe ao sujeito, algo lhe escapa sem que ele possa saber sua significação. O significante, assim como a carta, circula à revelia do sujeito: ninguém de fato o possui. E quando o significante/lettre escapa, deixa para traz um resto ilusório: o simulacro do significante ou da carta (um fac-símile da forma, mas não do conteúdo). Tomemos o exemplo do sonho dado por Lacan em A instância da letra no inconsciente para melhor ilustrar esse problema: as imagens oníricas manifestas são um enigma para aquele que sonha. E tal como um enigma, se nos detivermos no texto manifesto do sonho, jamais chegaremos a decifrá-lo (seremos eternamente enganados por ele). A tradução do sonho, sua resolução, se dá apenas pela escuta do significante que ali se esconde. No conto de Allan Poe, assim como na significação manifesta do sonho, os personagens são enganados na circulação da carta. O rei é enganado porque nada viu; a rainha viu, mas nada pôde fazer; o ministro nada viu e nada sabe da substituição de Dupin (Lacan 1966, p. 15). Diante

3 Lacan escreve: "Trata-se aqui desse ser que aparece apenas no lampejo de um instante no vazio do verbo ser, e eu disse que ele põe sua questão para o sujeito. O que isso quer dizer? Ele não a põe diante do sujeito, já que o sujeito não pode vir ao lugar em que ele a põe, mas ele a põe no lugar do sujeito" (Lacan 1966, p. 520). 
do mutismo de uns e da cegueira de outros, o significante circula e, nessa circulação, o sujeito é enganado pela substituição significante (e não pela substituição de significado). De carta em carta, ou, de significante em significante, mobiliza-se toda a trama na qual os sujeitos se colocam.

Para Lacan, a técnica freudiana da associação livre permitiria identificar a significação de manifestações psíquicas de origem inconsciente e ver nelas a propriedade de designar outras coisas diferentes do que significam imediatamente. A técnica inventada pelo psicanalista austríaco nos daria a chave da interpretação do sonho, permitindo apreender o seu segredo num discurso significante.

Tal como nos sonhos, significante e significado não se encontram necessariamente ligados. Segundo a analogia significante/ carta - significado/conteúdo da carta, podemos dizer que as pessoas se mobilizam pela carta/Lettre, independente do seu conteúdo. Do mesmo modo na linguagem: ao se separar do significado, o significante está livre para criar elos associativos com outros significantes (associações metafóricas e metonímicas). No início do Seminário 11, intitulado Os quatro conceitos fundamentais da psicanálise, Lacan afirma que o desligamento entre significante e significado é apresentado como aquele que permite a constituição do inconsciente. Nesse texto, o psicanalista francês nega a existência de um inconsciente primário, anterior à linguagem (que pré-exista independente do significante). Tudo o que há no inconsciente teve de chegar até lá. Esse caminho é possibilitado pelo recalcamento: este não atua sobre as formações não simbólicas; ao contrário, nele, a ligação entre significante e significado é rompida; o significante desaparece como tal, isto é, faz-se inconsciente. Lacan pode afirmar assim que a linguagem é condição do inconsciente e de seu conteúdo; que a linguagem ordena o inconsciente, organiza-o antes mesmo que o sujeito possa dizer algo.

"Mesmo antes de se estabelecer relações que sejam propriamente humanas, algumas relações já são determinadas. Elas se ligam a tudo o que a natureza possa oferecer como suporte, su- 
portes que se dispõem em temas de oposição. A natureza fornece, para dizer a palavra, significantes, e esses significantes organizam as relações humanas de modo inaugural, dando-lhes as estruturas, e as modelam." (Lacan 1973, p. 23).

O que queremos dizer é que o inconsciente em Lacan é constituído por cadeias de significantes inacessíveis ao sujeito. Por esse motivo, o discurso onírico, por exemplo, não faz sentido para aquele que sonha, pois está destituído de significado. A perda de significado é ao mesmo tempo a perda de todo o controle sobre o que seus significantes querem dizer - e o mesmo se daria com os ditos espirituosos e as patologias psíquicas. O trabalho da análise seria o de restituir para o paciente o discurso verdadeiro ou pleno - isto é, o discurso em seu significado. A técnica analítica da associação livre seria, desse modo, o instrumento capaz de reparar a ligação entre significante e significado.

Não é nossa intenção, contudo, dar a entender que o trabalho da análise, ao reparar a ligação entre significante e significado, faça com que o sujeito assuma o "controle total" sobre sua fala, sobre si. Ao contrário, o que afirmamos é que há algo anterior ao sujeito, ao inconsciente, à análise, algo da ordem do pré-sujetivo e do pré-político, a saber: o significante, que organiza, ordena, põe em série, determina a experiência analítica, as relações sociais e o próprio sujeito. O significante rege tudo o que é da ordem do humano por razões internas a ele; razões que permitem a Lacan dizer que o significante prevalece, que ele está sobre o significado. É nesse sentido que o psicanalista francês afirma, nos Quatro conceitos fundamentais da psicanálise, que "tudo surge da estrutura do significante" (Id., Ibid. 1973, p. 188)4.

4 De modo algum queremos dar a entender que o inconsciente a que Lacan se refere seja o desconhecimento passivo que pode, pela conversão ao saber, sair da ignorância. A consciência nada pode saber acerca do inconsciente, pois este é estruturalmente inacessível. O desconhecimento a que Lacan se refere é, ao contrário, ativo: é o da própria atividade do sujeito. Nesse sentido, Paulo Arantes escreve que "a constituição do sujeito é, a rigor, uma autoafecção" (Arantes 2003, p. 46). 
A ideia da linguagem como um fundo anterior ao seu pronunciamento, fundo fluido, em movimento, obscuro e lacunar, tal como expresso pela Carta roubada, não é exclusivo de Lacan. É um problema caro à filosofia francesa contemporânea (Foucault e Derrida são exemplos disso). Um dos mais eminentes autores do período a chamar a atenção para isso é Merleau-Ponty. Ele abre o seu texto "A linguagem indireta e as vozes do silêncio", presente no livro Signos, falando de Saussure. E sobre o caráter obscuro da linguagem, lemos: "Enfim, temos de considerar a palavra antes de ser pronunciada, o fundo de silêncio que não cessa de rodeá-la, sem o qual ela nada diria, ou ainda pôr a nu os fios de silêncio que nela se entremeiam" (Merleau-Ponty 1991, p. 47)5. Bento Prado Jr., em seu texto "A linguagem indireta ou o paradigma musical", escreve que já em Rousseau existe uma preocupação similar, na medida em que ele afirma uma modificação da linguagem baseada no movimento e na fluidez, que tem no paradigma musical seu modelo de linguagem. Dito de outro modo, a linguagem seria antes de mais nada um fluxo no qual não haveria determinações ou definições fixas, como quer a gramática e os dicionários, no qual todo sentido próprio acaba por se revelar figurado.

Se não nos cabe aqui investigar o lugar de Lacan frente a outros autores que tratam da concepção móvel e lacunar da linguagem, nos é, no entanto, lícito perguntar pela peculiaridade que esse tema assume no interior do seu próprio pensamento. Segundo Bertrand Ogilvie, em Lacan: o surgimento do conceito de sujeito, a originalidade do psicanalista francês está em trazer

5 E também na p. 43: "O sentido é o movimento total da palavra e é por isso que nosso pensamento demora-se na linguagem. [...] Logo, há uma opacidade da linguagem: ela não cessa em parte alguma para dar lugar ao sentido puro, nunca é limitada senão pela própria linguagem, e o sentido só aparece nela engastado nas palavras como a charada, só é compreendida mediante a intenção dos signos, que considerado à parte são equívocos ou banais, e apenas reunidos adquirem sentido".

6 Texto que serve de introdução à tradução brasileira do Ensaio sobre a origem das línguas (Unicamp) e que mais recentemente integra o livro A retórica de Rousseau (Cosac Naif). 
as questões colocadas no âmbito da filosofia para o da psicanálise. Essa é, segundo ele, a grande contribuição de Lacan, indissociável de sua concepção de desejo e de Outro ${ }^{7}$.

\section{$\mathrm{O}$ inconsciente e o desejo}

Retomemos, finalmente, a análise do conto de Poe sob a luz da concepção de desejo, e perguntemo-nos se não poderia ser inserido na circulação da carta algo que concerne ao volitivo. No conto, está claro que possuir a carta é ter poder: com a carta nas mãos, o ministro chantageia a rainha; tendo ela recuperado a carta, destrói-se a posição e o poder do ministro. Se a carta mobiliza os personagens e a relação entre eles, sua posse é determinante para isso. Não haveria também na própria circulação do significante o desejo de possuí-lo? Não é o significante que se quer? Com essa pergunta, entramos no campo da diferenciação entre desejo e demanda (désir e demande).

É bastante sabido que o corpo tem, em Freud, um papel fundamental para o psiquismo. Ao tomarmos o texto Pulsões e destinos da pulsão, vemos que é dele que brotam as pulsões (definidas ali como

7 Ogilvie afirma que não há uma contradição entre a filosofia e a psicanálise levada a cabo por Lacan: o sujeito lacaniano coloca-se na mesma direção inaugurada pela filosofia kantiana, a saber: a da "finitude constituinte" do sujeito, "posta em relevo pela 'revolução copernicana'." Contudo, o comentador francês afirma ainda que, se na Crítica da razão pura, toda exclusividade do saber foi atribuída ao sujeito kantiano (ou para usarmos os termos do filósofo de Königsberg, ao sujeito transcendental), Lacan prefere o caminho que leva da Primeira Crítica à Fenomenologia do Espírito, qual seja: o de "conduzir o sujeito ao seu lugar negativo de consciência desconhecedora". Ele continua: "Assim como o sujeito kantiano apreende, isto é, constitui o mundo dos fenômenos pelo jogo das formas a priori da sensibilidade e dos conceitos do entendimento, o sujeito lacaniano constitui o mundo dos objetos de seu desejo a partir da estrutura da linguagem que o determina intimamente". Tendo isso em vista, Ogilvie conclui que, por um lado, "se o sujeito kantiano é um sujeito transcendental" (ao menos no que diz respeito às Críticas), já que "a razão universal é a sua razão" e a sua atividade "não ser 'subjetiva', particular, mas a única fonte de objetividade possível"; por outro lado, em Lacan, o "lugar transcendental" não está no sujeito, mas no Outro (entendido como a "linguagem dada"). Se podemos falar em uma função transcendental em Lacan, para Ogilvie, ela não tem o seu princípio no sujeito - este é apenas seu efeito (Ogilvie 2005, p. 124-25). 
o conceito fronteiriço entre o anímico e o somático) e sua primeira aparição no psiquismo se dá no núcleo do inconsciente. Ao tratar das pulsões em Os quatro conceitos fundamentais da psicanálise, Lacan irá afirmar que não há pulsão sem experiência subjetiva, e que não há experiência subjetiva sem uma aproximação ao sentido. Quando afirma que tudo emerge da estrutura do significante, o psicanalista francês refere-se também ao desejo e à pulsão.

Não queremos com isso dizer que Lacan minimiza ou nega a importância do biológico. Em Lacan: a formação do conceito de sujeito, Bertrand Ogilvie afirma que já, desde a tese de Lacan (de 1936), podemos ver anunciado o programa que está por vir, a saber: o da dependência do sujeito. Lacan fala de uma precariedade essencial e originária, de uma indigência do ser humano logo ao nascer. Em seu escrito O estágio do espelho como formador da função do eu, ele descreve esse estado como o de "impotência motora" e "dependência da nutrição" do "pequeno homem nesse estágio infans" (Lacan 1966, p. 94). O caráter biológico do ser humano não lhe dá um lugar privilegiado na natureza - ao contrário, o biológico é o lugar da carência, da precariedade individual, da negatividade.

A insuficiência vital não será, contudo, o centro da investigação de Lacan; o objeto de sua investigação, segundo Ogilvie, será o ponto em que essa insuficiência se cruza com um campo oposto e assimétrico ao primeiro, a saber: o da universalidade do discurso. O objeto da investigação de Lacan é o ponto em que a indigência vital humana (percebida como uma brecha, uma falta) precipita a criança na linguagem - não para unicamente apontar a indeterminação do ser humano, mas para mostrar uma característica própria à ordem humana em geral, a saber: a de um lugar vazio pelo qual o sujeito tem acesso à linguagem. Lacan se interroga, assim, sobre os efeitos estruturantes do cruzamento da precariedade e do discurso na formação do sujeito.

Para o psicanalista francês, o discurso estaria em relação com a precariedade humana e a substitui em outro terreno. Isto 
porque a linguagem se prestaria a representar a ausência - representação que se dá em um plano distinto do biológico. Segundo Bentro Prado Jr.(2003), o fato de Lacan colocar todo o acento na linguagem lhe possibilita escapar da redução da ordem humana à natural (isto é, da cultura à natureza, da língua ao fisiológico etc.), redução que suprimiria a ordem antropológica que a psicanálise acabara de inaugurar.

O cruzamento do plano biológico com o do discurso nos permite diferenciar o que Lacan denomina desejo e demanda. A criança inicia sua existência no mundo como impotente e dependente da amamentação. Sua sobrevivência depende de um objeto específico: o leite. Lacan supõe assim uma fase inaugural na vida da criança em que ela se acha limitada a um único impulso: a demanda. Esta é caracterizada da seguinte forma: para uma necessidade sentida (a fome), pode-se oferecer um objeto que a satisfaça (o alimento - o leite). Wollheim, em O gabinete do Dr. Lacan, designa a demanda como um "estado intransitivo, no sentido que, quando o recém-nascido tem necessidades, nada se pode dizer a respeito, exceto que tem necessidades" (Wollheim 1990, p. 205). É apenas com a aquisição do símbolo (e a entrada no campo da linguagem) que a criança torna-se capaz de representar para si um objeto. Ela passará assim a ter vontade de, pois adquiriu um sistema de representação. Lacan fala assim de um objeto causa do desejo (o objeto $a-a$ minúsculo [de autre]), sempre ausente, jamais designado por um objeto real, e que condiciona radicalmente a dimensão do desejo à presença do Outro (Autre), isto é, à ordem simbólica determinante do sujeito, que o aliena de si mesmo. Esse objeto causa do desejo não é o alimento ou a sua lembrança, mas um objeto perdido, faltante (o seio), que fixa a fantasia. Ele não é um objeto real, um objeto da demanda, que possa se oferecer na experiência, mas um objeto que determina a singularidade de cada sujeito. Ousar ceder de seu desejo (céder sur son désir), ou melhor, abrir mão dele é renunciar à sua própria subjetividade. 
o conceito fronteiriço entre o anímico e o somático) e sua primeira aparição no psiquismo se dá no núcleo do inconsciente. Ao tratar das pulsões em Os quatro conceitos fundamentais da psicanálise, Lacan irá afirmar que não há pulsão sem experiência subjetiva, e que não há experiência subjetiva sem uma aproximação ao sentido. Quando afirma que tudo emerge da estrutura do significante, o psicanalista francês refere-se também ao desejo e à pulsão.

Não queremos com isso dizer que Lacan minimiza ou nega a importância do biológico. Em Lacan: a formação do conceito de sujeito, Bertrand Ogilvie afirma que já, desde a tese de Lacan (de 1936), podemos ver anunciado o programa que está por vir, a saber: o da dependência do sujeito. Lacan fala de uma precariedade essencial e originária, de uma indigência do ser humano logo ao nascer. Em seu escrito O estágio do espelho como formador da função do eu, ele descreve esse estado como o de "impotência motora" e "dependência da nutrição" do "pequeno homem nesse estágio infans" (Lacan 1966, p. 94). O caráter biológico do ser humano não lhe dá um lugar privilegiado na natureza - ao contrário, o biológico é o lugar da carência, da precariedade individual, da negatividade.

A insuficiência vital não será, contudo, o centro da investigação de Lacan; o objeto de sua investigação, segundo Ogilvie, será o ponto em que essa insuficiência se cruza com um campo oposto e assimétrico ao primeiro, a saber: o da universalidade do discurso. O objeto da investigação de Lacan é o ponto em que a indigência vital humana (percebida como uma brecha, uma falta) precipita a criança na linguagem - não para unicamente apontar a indeterminação do ser humano, mas para mostrar uma característica própria à ordem humana em geral, a saber: a de um lugar vazio pelo qual o sujeito tem acesso à linguagem. Lacan se interroga, assim, sobre os efeitos estruturantes do cruzamento da precariedade e do discurso na formação do sujeito.

Para o psicanalista francês, o discurso estaria em relação com a precariedade humana e a substitui em outro terreno. Isto 


\section{Bibliografia}

ARANTES, P. E. "Hegel no espelho do Dr. Lacan". In: SAFATLE, V. [org.] Um limite tenso: Lacan entre a filosofia e a psicanálise. São Paulo: Editora da UNESP, 2003.

DOR, J. Introdução à leitura de Lacan: o inconsciente estruturado como linguagem. Porto Aletre: Artmed, 2003.

FAUSTO, R. "Dialética e psicanálise”. In: SAFATLE, V. [org.] Um limite tenso: Lacan entre a filosofia e a psicanálise. São Paulo: Editora da UNESP, 2003.

FREUD, S. Zur Ätiologie der Hysterie. In: Gesammelte Werke. vol.

1. Frankfurt am Main: Fischer Verlag, 1999.

Die Träumdeutung. In: Gesammelte Werke. vol. 2/3. Frankfurt am Main: Fischer Verlag, 1999.

Drei Abhandlungen zur Sexualtheorie. In: Gesammelte Werke. vol. 5. Frankfurt am Main: Fischer Verlag, 1999.

Triebe und Triebschicksale. In: Gesammelte Werke. vol. 10.

Frankfurt am Main: Fischer Verlag, 1999.

LACAN, J. Escritos. Rio de Janeiro: Zahar, 1998.

Écrits. Paris: Seuil, 1966.

O seminário, livro 11: Os quatro conceitos fundamentais da psicanálise. Rio de Janeiro: Zahar, 2008.

Le séminaire 11: les quatre concepts fondamentaux de la psychanalyse. Paris : Seuil, 1973.

O mito individual do neurótico. Rio de Janeiro: Zahar, 2008. "Hommage à Marguerite Duras, Du ravissement de Lol

V. Stein». In : Cahiers Renaud-Barrault, Paris, Gallimard, 1965, n 52, pp. 7-15 - Disponível em: <www.litt-and-co.org/ citations_SH/l-q_SH/lacan-duras.htm>. Acesso em 19 de novembro de 2012.

MERLEAU-PONTY, M. Signos. São Paulo: Martins Fontes, 1991. MONZANI, R. "A teoria freudiana dos sonhos". In: FULGENCIO, L; SIMANKE, R. Freud na filosofia brasileira. São Paulo: Escuta, 2005 . 
OGILVIE, B. Lacan: la formation du concept de sujet. Paris: PUF, 2005 .

POE, E. A. «A carta roubada”. In: Histórias extraordinárias. Trad. José Paulo Paes. São Paulo: Companhia das Letras, 2008.

PRADO Jr., B. "Lacan: biologia e narcisismo ou A costura entre o real e o imaginário”. In: SAFATLE, V. [org.] Um limite tenso: Lacan entre a filosofia e a psicanálise. São Paulo: Editora da UNESP, 2003.

A retórica de Rousseau: e outros ensaios. São Paulo: Cosac \& Naify, 2008.

WOLLHEIM, R. "O gabinete do Dr. Lacan”. In: SOUZA, P. C. Sigmund Freud e o gabinete do Dr. Lacan. São Paulo: Brasiliense, 1990. 